\title{
Academic Staff Perceptions of Service Quality Improvement in Ethiopian Public Higher Education Institutions
}

\author{
Solomon Lemma Lodesso (PhD) \\ Assistant professor, Hawassa University, School of Education and Training \\ Soleysus7@gmail.com \\ EJ Van Niekerk \\ Professor, University of South Africa, Department of Educational Leadership and Management \\ vniekej@unisa.ac.za \\ CA Jansen \\ Associate professor, Department of Educational Leadership and Management, \\ College of Education, University of South Africa, Pretoria, South Africa \\ H Muller \\ Research Support Consultant: Statistics Department of Interdisciplinary Research, \\ College of Graduate Studies, University of South Africa, Pretoria, South Africa
}

Doi:10.5901/mjss.2014.v5n14p435

\section{Abstract}

The article explores academic staff's perceptions of service quality improvement in public higher education institutions in Ethiopia. For this purpose, a mixed research methodology was employed collecting data from academic staff and final year students at public higher education institutions using the SERVQUAL scale and through focus group interviews. The perceptions of academic staff are reported on in this article. The collected data were analysed using both descriptive and inferential statistics. The research findings indicated that all dimensions of the service quality improvement initiatives were perceived by academic staff to be very poor. Recommendations are made on the reliability, tangibles, empathy, responsiveness, and assurance dimensions of service delivery featuring in the SERVQUAL scale.

Keywords: Service quality improvement; Ethiopian Public Higher Education institutions; SERVQUAL; perceptions; Service quality dimensions.

\section{Introduction}

Ethiopian higher education has changed extensively over the last two decades. The number of higher education institutions and the intake capacity of undergraduate degree programmes in public higher education are increasing rapidly (Ministry of Education (MoE), 2009). However, the rapid increase in the gross enrolment rate has affected the overall quality of educational activities, particularly in the context of severely limited resources. The Ethiopian government has therefore made it one of their top priorities to address the issues of quality in the education sector (Ministry of Education (MoE), 2005; World Bank, 2004).

The Ministry of Education (MoE) is currently engaged in a highly motivated effort to reform the country's higher education system so that it contributes to the country's economic development and poverty reduction strategies. Reform in Ethiopian higher education includes expansion and reform programmes addressing many aspects. Expansion of the higher education section includes the opening of new universities, establishing supporting agencies such as the Higher Education Relevance and Quality Agency (HERQA), a Higher Education Strategic Centre (HESC) and the Educational Quality Improvement Programme (EQUIP), introducing new courses and curricula, making new funding arrangements, acquiring student contributions by means of cost sharing, building the necessary infrastructure, improving service quality through the implementation of BPR (Business Process Re-engineering), recruiting new staff, and developing and 
procuring teaching materials (Ayalew, Dawit, Tesfaye \& Yalew, 2009; Saint, 2004; Teshome, 2003).

According to Zafiropoulos and Vrana (2008), HEls must understand what service quality stakeholders need and what quality attributes are demanded by stakeholders in order to improve service quality and to satisfy stakeholders. For Berry and Parasuraman (1997), quoted by Shah (2009), institutions can improve the quality of the service they offer if they listen to and take cognisance of the experience of stakeholders.

Assessing the extent of academic staffs' satisfaction regarding service quality delivery in Ethiopian higher education is currently not common practice despite the fact that higher education institutions in the country are implementing quality improvement programmes vigorously (Solomon 2013). Most of these improvement initiatives have been the result of external and internal pressures by constituent stakeholder groups to respond to their needs and priorities. In 2008, service quality improvement initiatives in Ethiopian public universities started implementing BPR (Business Process Re-engineering) to effect a fundamental change in the current business process, jobs and structures, management and measurement systems, values and beliefs with the aim of increasing quality and productivity that focus on customer satisfaction. This was done by improving service quality, increasing competitiveness and dealing with the rapidly changing environment (Vakola and Rezgui, 2000). However, as to the knowledge of the researchers, there has been no study to date that has attempted to investigate the various stakeholders' perceptions of these quality improvement initiatives in Ethiopian public higher education institutions (PHEls).

Accordingly, the purpose of this article is to investigate the implications of stakeholders' perceptions regarding the service quality improvement initiatives at Ethiopian PHEls.

In the light of the above background and purpose statement the specific objectives reported on are to:

- Gauge perceptions held by academic staff of the service quality improvement initiatives in Ethiopian PHEls;

- Point out the gap between the expectations and perceptions of service quality improvement initiatives;

- Investigate areas that are considered by academic staff crucial in improving service quality in PHEIs;

- Assess whether the SERVQUAL scale is an appropriate and reliable measuring instrument of service quality in Ethiopian public higher education institutions.

\section{Importance of Quality Improvement in HEls}

With increased national and international competition and greater stakeholder expectations for quality service/products, organisations are engaged in the improvement of both quality and stakeholders' satisfaction (Mizikaci, 2006; Gapp \& Fisher, 2006; Koslowski, 2006). In the present competitive market, the success of organisations depends on the quality of services rendered. According to Mehralizadeh and Massoud (2010), organisations are now shifting their focus to comprehensive quality improvement to cope with the demand of markets. In support of this idea, Smith et al. (2007) proclaim that HEls are facing similar challenges due to rapidly changing technology, growing international and national competition for students, staff, research output, accountability by accrediting agencies and the public.

Even though the reasons for quality improvement vary from organisation to organisation, Johnston and Kong (2011) contend that the major reasons for improving service quality in HEls are concerned with improvement of stakeholder satisfaction and winning their loyalty, increasing confidence of stakeholders in the institutions and developing a strong attachment with customers.

Brysland and Curry (2001) and Jongbloed et al. (2008) also note that knowledge of what satisfies stakeholders and a consideration of their role in society are important steps in quality improvement initiatives for HEls in the delivery of service quality and the assessment of their relationships with different stakeholders. Chen, Yang, Shiau and Wang (2006) note that employee satisfaction in their current working environment leads to a greater willingness and efficiency in performing organisational activities. They continue by declaring that the degree of teacher satisfaction has an influence on the performance of the institutions. Greater stakeholder satisfaction leads to an improvement in loyalty, the further consumption of the service and invitations from other stakeholders (Chen, Yang, Lin \& Yeh, 2007; Juga \& Juntunen, 2010).

Identifying stakeholders' perceptions of service quality is an important matter for HEls (Gallifa \& Batalle, 2010). According to Giertz (2000) and Shah (2009), stakeholder perception of quality is one of the determinants of their attitude towards quality work and based on their perception of quality, they will be attracted to some products/services. In support of this view, Faganel (2010) observes that academic staff's service quality perceptions are improved by ensuring that the service is accurate, reliable and clear to them during service delivery. In return, this improvement leads to higher satisfaction. He furthermore remarks that a negative response from stakeholders is the result of a failure to meet or exceed their expectations. This serves as an indication to management where changes need to be made and also 
pinpoints areas for further improvement.

In general, quality improvement, as set out in the preceding pages, helps higher education institutions to attract academic staff and to create good perceptions of the service delivered. Thus, to be competitive both nationally and internationally, quality improvement in HEls is a prerequisite. In order to carry out quality improvement activities in HEIs, different quality improvement methods are used.

The most commonly used methods in quality improvement initiatives are: Total Quality Management (TQM); Continuous Improvement (Cl); Business Process Re-engineering (BPR); Business Process Improvement (BPI); Process Re-engineering (PR); Benchmarking (BM); Theory of Constraints (TOC) and Organisational Restructuring (OR). All these methods are aimed at improvement initiatives of operations; however, they differ in terms of implementation and scope (Grunberg, 2003). The Ethiopia higher education institutions implemented BPR as quality improvement technique that will be discussed below.

\section{Business Process Re-Engineering (BPR)}

Business Process Re-engineering (BPR) as a quality improvement initiative is commonly applied in the business sector for attaining efficiency, effectiveness and for making the activities customer-focused. Vakola and Rezgui (2000) state that BPR is used in quality improvement initiatives for a number of reasons. Firstly, BPR methodology provides the means of codifying experience, knowledge and ideas that can be evaluated and tested. Secondly, BPR methodology allows for planning and monitoring activities in the institutions. It enables them to develop a clearer picture of its core processes and associated problems. Thirdly, those involved or affected by the re-engineering activity have a clear understanding of their roles and tasks. In addition to that, it facilitates communication between those individuals who are leading BPR and different parties with the result that progress is seen as a result of monitoring activity of the overall process reengineering. Finally, BPR allows for the identification and development of standards for required skills. The key skills required for BPR include process modelling, organisational development techniques and the skills to deal with resistance to change.

In 2008 BPR was implemented in PHEls to bring improvement in service delivery and to satisfy stakeholders. Before the implementation of BPR, the BPR team was organized in each university to assess the existing situation in their university. Different BPR teams found that the service delivery was stakeholder oriented, but they also identified many problems related to service delivery. Regarding this re-design process, the committees of different universities identified certain points/areas for improvement. For example the committees of the Hawassa and Mekelle Universities have made the following suggestions to provide the best service to satisfy its stakeholders (HU, 2009b; MU, 2008):

- The curriculum ownership should belong to an academic unit, but it should be accessible to all students and staff online, with sufficient course information on academic content, means of assessment and learning objectives.

- A regular monitoring system for curricula should be in place.

- Administrative costs should be reduced or eliminated and work flow processes should be simplified.

- Services like waste management and landscaping should be outsourced to reliable service providers and monitored tightly by the university.

- Student disciplinary guides should be made available to students, and student disciplinary measures need to be taken when necessary.

- Reception areas and other marketing centres should be restructured as income generating units.

\section{Service Quality Models for Measuring Service Quality Improvement}

In literature on education service quality, a number of models have been proposed, inter alia the SERVQUAL model (Parasuraman, Zeithaml \& Berry, 1988), the SERVPERF model (Cronin \& Taylor, 1992), the Evaluated Performance (EP) model (Teas, 1993a, b), the IPA model (Martilla \& James, 1977) and the HEdPERF model (Firdaus, 2006).

Even though there is no one fit model for all situations, the selection of the model depends on the suitability of the model. This research used the modified SERVQUAL model to measure perceptions on the improvement initiatives of service quality in Ethiopian higher education by identifying the gaps between academic staff expectations and their perceptions of service quality.

The SERVQUAL model is easy to apply to the public sector, is statistically valid, is designed to identify key service quality dimensions and allows for the determination of perception, expectations and gaps between the perceptions and 
expectations (Brysland \& Curry, 2001). Brysland and Curry (2001) add that the SERVQUAL model is a tried and tested model used reasonably often as a benchmarking tool. It was also developed in response to a lack of conclusive measuring tools designed for gauging service quality. The SERVQUAL model reveals the gap between customer perceptions and expectations of service quality, in order to determine the perceived service quality and to target these identified gaps for improvement (Parasuraman et al., 1988; Faganel, 2010; Chen et al., 2007; Nadiri, Kandampully \& Hussain, 2009; Brysland \& Curry, 2001; Chen et al., 2006; Quinn et al., 2009; Wright \& O'Neill, 2002).

In their later investigation, Parasuraman et al. (1988) refined the scale by removing overlapping quality dimensions and they then identified twenty-two attributes distributed over five dimensions. Using these attributes as questions in the SERVQUAL model, the gap between the score of perception of the performance and the score of expectation in each dimension can be calculated.

They labelled and defined the five new dimensions as follows (Parasuraman et al., 1988):

- Tangibles: the physical facilities and surroundings, the equipment used in the delivery of the service and appearance of the personnel (number of items: 4).

- Reliability: the ability of the service provider to deliver dependable and accurate service as promised (number of items: 5).

- Responsiveness: the institution's willingness to assist its stakeholders by providing prompt service (number of items: 4).

- Assurance: the service provider's knowledge and ability to provide confidence to stakeholders (number of items: 4).

- Empathy: readiness for provision of individualised care and attention to stakeholders (number of items: 5).

These dimensions are represented in the model below:

Figure 2.2: Determinants of perceived service quality

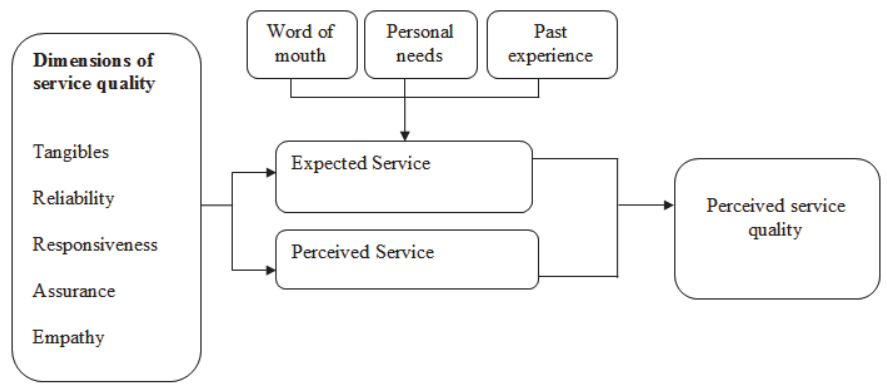

Source: Parasuraman, et al.,1985:48

Despite its popularity, the SERVQUAL model has been criticised (for example, Cronin \& Taylor, 1992; Teas, 1993a; Joseph \& Joseph, 1997; O'Neill \& Palmer, 2004; Chen et al., 2006). Because of such criticism of the SERVQUAL model, this research makes use of the modified SERVQUAL model (Parasuraman et al., 1991). To complement the finding of SERVQUAL model to overcome the weak points of the traditional SERVQUAL model and to identify areas for improvement that were not identified by the SERVQUAL model qualitative data (focus group discussion) were used.

\section{Methodology}

This study examined the perception of academic staff on service quality improvement in Ethiopian higher education institutions. It follows a mixed method, quantitative and qualitative research strategy.

\subsection{Sampling}

The population for this study consisted of academic staff of twenty two Ethiopian universities (MoE 2011 confirms this number: Nine universities established prior to 1998 and thirteen, later than 1998). Academic staff members from four of these universities were sampled to participate in the quantitative component of the study. Sampling consisted of 
multiphase sampling, namely stratified, simple random and systematic random sampling (Lodico et al., 2006). In the first sampling phase, the date of university establishment - prior to, or, after 1998 - was used as stratification criterion to stratify universities by establishment date, and then randomly select two 'new' (of 13) and two 'old' universities (of 9) from the population. In the next phase of sampling, a random sample of 40 academics per selected university $(4 \times 40=160)$ was sampled using stratified and systematic random sampling. Colleges within universities were regarded as strata and a predetermined number of staff per college was systematically sampled per university by randomly selecting a starting position on each college staff list and from there on systematically sampling every $n^{\text {th }}$ staff member on the list (where $n$ is calculated as the number of college staff members divided by the required number of staff per college).

An additional forty participants were also selected from the four selected universities to participate in the qualitative leg of the research. In this instance convenience sampling was used to select key participants for focus group interviews.

\subsection{Measuring instruments}

In the quantitative research leg of the research, the 1991-adapted, standardised SERVQUAL questionnaire was used to measure participant perceptions. The SERVQUAL scale was adapted for the Ethiopian setting by translating the questionnaire to Amharic, the native language of Ethiopia, and adapting terminology to accommodate Ethiopian educational culture (This included minor adaptations, for example, Ethiopian students refer to "lecturers" as "teachers"). As discussed in paragraph 4, "Service quality models for measuring service quality improvement", the questionnaire probes perceptions and expectations on five service dimensions of tangibles, reliability, responsiveness, empathy and assurance. These dimensions are each evaluated in subsets of four or five questions (of the total of twenty two) that comprise the questionnaire. Participant perceptions are evaluated on a seven-point Likert rating scale, ranging from a score of 1 indicating "strong disagreement" to 7, indicating "strong agreement". The principle was followed that questionnaire completion was voluntarily and anonymously.

For the qualitative leg of the research, a semi structured interview schedule was prepared. It was prepared prior to focus group interview sessions and once the quantitative results became known. In this way interviewee reflection on quantitative findings could be included in the study. Four group interviews were held at the four universities.

\subsection{Variable definition and quantitative analysis strategy}

Of interest to the quantitative research were measurements of the discrepancy, or gap, between participants' expectations and experiences on five service delivery indicators or dimensions. If no significant discrepancies were indicated service satisfaction could be reported. The analysis strategy therefore aimed at evaluating such discrepancy measures (referred to as "gap measures"). The gap measures were calculated as the difference between mean expected and experienced (perceived) responses (section 6.4).

However, prior to the calculation and evaluation of the five service-gap measures on tangibles, reliability, responsiveness, empathy and assurance in service delivery, the underlying structure and the internal consistency reliability of the service model data had to be verified. To this end factor analyses (section 6.2) and scale reliability testing (section 6.3) were conducted on the response ratings of participants.

\section{Results of the Quantitative Investigation}

\subsection{Exploratory analysis}

The quantitative result revealed that the gender composition of 155 sampled academic staff consisted of $90.3 \%$ males and $9.7 \%$ females. This illustrates that female academic staff is very limited in Ethiopian public HEls. With respect to the academic status, the majority of the academic staff, roughly $70 \%$ were lecturers, $17.4 \%$ graduate assistants and $2.6 \%$ assistant or full professors. These findings verify Taye's (2008: xxi) findings that Ethiopian higher education is in need of senior academic staff. The majority of the sampled academic staff (65.8\%) had less than five (5) years experience. Only $30.4 \%$ had between 6 to 10 years experience and the remaining 3.8\% had more than ten (10) years teaching experience in higher education.

\subsection{Factor analysis results}

In this study factor analysis served a dual purpose: in the first instance factor analysis investigated the dimensionality of 
the underlying structure of the response data, and in the second instance compared this Ethiopian data structure to that of independent SERVQUAL studies.

Maximum Likelihood factor analysis with an oblique rotation (Field, 2005) was used as factor extraction and rotation method. The oblique transformation technique was included because there was reason to believe that the factors that underlie the Ethiopian service quality model would probably be interdependent. This decision was based on the findings of an independent study by Parasuraman et al. $(1988 ; 1991)$ who report on interrelated factors within a similar context.

In this study under discussion, several factor analyses were executed with differing numbers of factors extracted. Table 1 summarises the results of these analyses. Apart from the number of factors extracted the table reports on Bartlett's Chi-square statistic (a measure of whether more than one factor should be extracted); the Kaiser Meyer Olkin criterion (a measure of sampling adequacy); and several criteria to guide a decision on the number of factors to extract. These include; the Akaike criterion; the Schwarz Bayesian Criterion; and the Tucker Lewis reliability coefficient (Field 2005). Apart from these statistics the point of inflection on the scree plot; the number of eigenvalues greater than one (displayed in each analysis printout and not included in this article); and the practical interpretability of the extracted factors were considered in deciding on the best fit factor analysis model.

Table 1: Results of six factor analyses with one to six factors extracted to decide on the model of best fit. (MSA $=0.95$ in all analyses)

\begin{tabular}{|c|c|c|c|c|c|c|c|c|c|c|}
\hline \begin{tabular}{|c|}
$\#$ \\
Factors \\
\end{tabular} & $\begin{array}{c}\text { Bartlett Chi- } \\
\text { sq }\end{array}$ & $\begin{array}{c}\text { Pearson } \\
\text { Chi-sq }\end{array}$ & Akaike & $\begin{array}{c}\text { Schwarz } \\
\text { BC }\end{array}$ & $\begin{array}{l}\text { Tucker Lewis R- } \\
\text { coefficient }\end{array}$ & Factor1 & Factor2 & Factor3 & \begin{tabular}{|l} 
Factor4 \\
\end{tabular} & Fact $5 \& 6$ \\
\hline 1 & $\begin{array}{c}9492.20^{* \star *} \\
(231)\end{array}$ & 1368.8 & 950.81 & -13.10 & 0.84 & \begin{tabular}{|c} 
q1-4 \\
q5-9 \\
q10-13 \\
q14-17 \\
q18-22
\end{tabular} & & & & \\
\hline 2 & $\begin{array}{c}9492.20^{* \star \star} \\
(231)\end{array}$ & 1087.49 & 711.49 & -191.15 & 0.88 & $\begin{array}{l}\text { q10-13 } \\
\text { q14-17 } \\
\text { q18-22 }\end{array}$ & $\begin{array}{l}\text { q1-4 } \\
\text { q5-9 }\end{array}$ & & & \\
\hline 3 & \begin{tabular}{|c|}
$9492.20^{\star \star \star}$ \\
$(231)$ \\
\end{tabular} & 747.57 & 411.57 & -395.05 & 0.92 & $\begin{array}{l}\mathrm{q} 10-13 \\
\mathrm{q} 14-17 \\
\end{array}$ & $\begin{array}{c}\mathrm{q} 1,2,4 \\
\mathrm{q} 5-8\end{array}$ & q19-22 & & \\
\hline 4 & $\begin{array}{c}9492.20^{\star \star \star} \\
(231)\end{array}$ & 506.08 & 208.08 & -507.31 & 0.94 & $\begin{array}{l}\text { q10-13 } \\
\text { q14-17 }\end{array}$ & q5-8 & q19-22 & $\mathrm{q} 1,2,4$ & \\
\hline 5 & $\begin{array}{c}9492.20 \star \star \star \\
(231)\end{array}$ & 399.67 & 137.67 & -491.29 & 0.95 & $\begin{array}{c}\text { q10-13 } \\
\text { q14 }\end{array}$ & q5-8 & q 20-22 & $q 1,2,4$ & q17 \\
\hline 6 & $\begin{array}{c}9492.20^{\star \star *} \\
(231)\end{array}$ & 294.51 & 66.51 & -480.84 & 0.96 & q5-9 & \begin{tabular}{|l|}
$\mathrm{q} 11-13$ \\
$\mathrm{q} 14,15$
\end{tabular} & q19-22 & $\mathrm{q} 1,2,4$ & $\begin{array}{c}\mathrm{q} 10 \\
\text { (F6: q17) }\end{array}$ \\
\hline \multicolumn{8}{|c|}{$\begin{array}{l}\text { Legend: } \\
\text { KMO/ MSA: Kaiser Meyer Olkin measure.(Should be > 0.8, (Kaiser (1970)) } \\
\text { Akaike : Akaike criterion (smallest is best) } \\
\text { Schwarz BC: Schwarz Bayesian Criterion (smallest is best) } \\
\text { Tucker-Lewis R-Coef: Tucker Lewis reliability coefficient (Closest to 1.0) } \\
\text { Fact1-Fact5, F6: Factors } 1 \text { - } 6 \text { extracted in factor analysis models (where pi, i = 1-22, refers to } \\
\text { perceptions ratings on q1-q22) } \\
\text { References: Schwarz J (2011), Field A (2001), Hatcher L.1994 }\end{array}$} & \multicolumn{3}{|c|}{$\begin{array}{l}\text { Questionnaire statements } \\
\text { describing SERVQUAL factors/ } \\
\text { or constructs } \\
\text { q1-q4 :Tangibles } \\
\text { q5-q9: Reliability } \\
\text { q10-q13: Response } \\
\text { q14-q17: Assurance } \\
\text { q18-q22: Empathy }\end{array}$} \\
\hline
\end{tabular}

Table 1 indicates that the Kaiser-Meyer-Olkin's measure of sampling adequacy was 0.95 for all models. This value is greater than 0.8, which, according to Schwarz (2011:26), indicates that the data of the current study can be analysed by means of factor analysis. Furthermore, the indicators listed in Table 1 jointly indicate to models with either four or five factors extracted as models of best fit: Pearson Chi-square statistic, Akaike's criterion and Schwarz's Bayesian criterion all decrease in value as the number of factors increases. In these cases the Tucker-Lewis $r$ coefficients approach a value of one which indicates to satisfactory factor extraction. (SAS/STAT User Guide, 1999).

The final decision on the model of best fit for the service quality data was based on the interpretability of the extracted factors: the factors of the four-factor model rendered the best interpretable factors with factor 1 describing the SERVQUAL dimensions of responsiveness and assurance; factor 2 the SERVQUAL dimension of reliability; factor 3 the SERVQUAL dimension of empathy; and factor 4 the dimension of tangibles (excluding question 3). The fact that two 
SERVQUAL dimensions, namely responsiveness and assurance, loaded onto factor 1 for the four-factor model, agree with the earlier statement by Parasuraman et al. (1988) that SERVQUAL dimensions/ factors are interrelated. These findings are furthermore in line with Mostafa (2007); Fernandez et al. (2005); Ramseook-Munhurrun et al. 2009); Wright \& O'Neill (2002) and Miao, Jiaxin \& Jinlin (2007) who all suggest that the SERVQUAL dimensions can be reduced to lesser.

\subsection{The gap between expectations and experience: Calculation of perceived and experienced service dimension scores}

These measures of service quality - referred to as service construct (or dimension) scores - were calculated for each service quality dimension. A particular dimension score (either experienced or expected) was calculated as the mean rating response of the subset of rating responses reported by an individual for the particular expectation or experienced service dimension. The gap score, calculated as the difference between experienced and expected individual scores, was calculated as well. Table 2 lists the academic staff's mean perceived, expected and gap service dimension scores and associated standard deviations.

Before any deductions could be made regarding discrepancies between expectations and experiences of service quality measured for the five aspects of service quality, the null hypothesis that the mean service gap score for a particular service dimension was zero (this implies that perceptions and expectations for a service dimension did not differ significantly) had to be tested. This was tested by calculating the Satterthwaite statistic (unequal variances) for each service dimension. These statistics and associated significance levels are indicated in Table 2 as well.

Table 2: Mean SERVQUAL service dimension expected and experienced scores and mean gap scores. The Satterthwaite statistics for $\mathrm{HO}$ : gap $=0$ and associated significance levels are included.

\begin{tabular}{|c|c|c|c|c|c|c|c|}
\hline \multirow{2}{*}{ Service dimensions } & \multicolumn{2}{|c|}{ Perceived experience } & \multicolumn{2}{|c|}{ Expectation } & \multicolumn{2}{|c|}{ Gap } & \multirow{2}{*}{$\begin{array}{c}\text { Satterthwaite statistic: } \\
H_{0}: \text { gap }=0\end{array}$} \\
\hline & Mean & Std & Mean & Std & Mean & Std & \\
\hline Tangibles & 3.38 & 1.19 & 6.44 & 0.62 & -3.07 & 1.39 & $-68.74^{\star \star \star}$ \\
\hline Reliability & 2.74 & 1.14 & 6.45 & 0.64 & -3.71 & 1.35 & $-67.93^{\star \star \star}$ \\
\hline Responsiveness & 3.47 & 1.09 & 6.38 & 0.65 & -2.92 & 1.27 & $-59.68^{\star \star \star}$ \\
\hline Assurance & 3.46 & 1.17 & 6.46 & 0.68 & -3.00 & 1.43 & $-58.57^{\star \star \star}$ \\
\hline Empathy & 3.13 & 1.06 & 5.08 & 0.49 & -1.94 & 1.18 & $-61.67^{\star \star \star}$ \\
\hline
\end{tabular}

Table 2 indicates that on all the quality service dimensions, perceived experience fell statistically significantly short of expectations. The statistical significance associated with the null hypothesis on all dimensions was statistically highly significant and the alternative hypothesis of a difference between expectations and perceived experience was accepted in each case. In general it can therefore be deduced that academic staff was not satisfied with service delivery (The mean gap scores on all service dimensions were negative).

Dissatisfaction was also reported in similar independent studies - barring that mean service dimension gap scores were less pronounced. Literature offer the following examples of overall mean gap scores: Smith et al. (2007), -1.3 for staff in the UK; Pansiri and Mmereki (2010), -2.80 in Uganda; Fernandez and Bedia (2005), -0.24; Zafiropoulos and Vrana (2008), -1.02 (for students) and -1.08 (for staff), in Greece; Wang, Wang and Zhao (2007) , -0.72 (hotel staff); Brysland and Curry (2001), -1.64 (service sector); and Ramseook-Munhurrun et al. (2009), also reported a negative score in Mauritius.

The deduction can thus be made that the statistically significant negative service gaps scores indicate that respondents' expectations are higher than what they perceive to experience. Table 2 is a clear indication that academic staff expected more reliable services, quality tangibles of services, assured services, reliable responses to service requests and empathy when serviced, in that order, when services are requested.

\section{Results of the Qualitative Data Analysis}

Specific questions were posed to academic staff during focus group discussions to obtain a more comprehensive understanding of the nature of service dissatisfaction.

Quantitative results indicated that the greatest discrepancy between expected and experienced service delivery was expressed regarding the reliability of services - the service reliability dimension. Issues raised in this regard included: 
- A lack of commitment of service providers.

- Departmental thinking instead of university wide thinking

- Unsuitable appointments in key positions.

- Bureaucratic systems that follow conventional rather than systems based on BPR principles.

- Supportive staff shortages.

- A resistance to change by especially the long-employed older component of the service work force.

- Insufficient or ineffective training in optimizing operational administrative processes.

- Unrealistically high expectations of the stakeholders.

- No motivating incentives for service staff.

A narrative of one of the academic staff in this respect is insightful:

\begin{abstract}
"Some of the staff are demoralised because of losing their previous position. One of the BPR principles is to capacitate workers for the position by giving training. Without doing this some workers are lowered from their previous position and assigned to a lower status. As a result they become demoralised and unwilling to provide services to customers as promised".
\end{abstract}

Similar research by BPR teams at Mekelle University (MU 2008) also reported service providers' lack of commitment, poor teamwork, unnecessary procedures and poor governance as reasons for service delivery dissatisfaction.

In the current study the aspect of reliable services that dealt with "keeping promises to do something by a particular time' was also run by the interviewees who positively affirmed the quantitative results of dissatisfaction with the reliability of services (gap score of -3.71). One interviewee for example stated that,

"If you ask them to buy something for your office, they promise to supply you within one or two days but sometimes you can't even get it at the end of the year. Such problems are mostly observed in the corporate finance and procurement and purchasing department".

Perceptions of unreliable service focused in particular on the corporate finance, procurement and purchasing departments of universities. As one of the interviewees commented,

"A person disgruntled with somebody or something cannot render an equitable service. For example, one day, we went to the finance department to collect our pay but we had to wait for the paying teller for several hours. Later he came but he told us that we had to come back in the afternoon because the morning time was over. We went there in the morrow (next day) but again he told us that he was unable to pay us for he had to go to the bank and informed us to come later. We came back to our office, being entirely dissatisfied for the pay hadn't been made. We were very disappointed with the paying teller's behaviour and cancelled the day's lectures. This clearly demonstrates that the staff member is not responsibly discharging the duties entrusted to him. He is not a conscientious worker".

The general finding that promises are not honoured, is verified by BPR teams from several universities (MU 2008; HU 2008). These teams agree that service support structures for teaching and learning are inadequate, time consuming and cumbersome resulting in service providers' inability to deliver what was promised. The Mekelle University BPR team (MU 2008) indicates that the issue of unsatisfactory financial management is acknowledged by university authorities, but that change-implementation is slow or none).

Interviewees offered explanations for broken promises that indicated that staff only attend to work when the relevant stakeholder was present in their offices; that the inclusion of a third party in service delivery (another service officer) only slows the service delivery process; that the workload of service providers were too high; that service providers had limited resources and lacked good governance; that a lack of empathy towards the receiver of services were experienced; and that service providers had no performance incentives to motivate them to deliver a better service.

In addition to the reliability aspect of service quality, the issue of tangibles in service delivery was indicated as an area that did not live up to expectations. (A quantitative measure of the tangible service dimension dissatisfaction was indicated by the tangibles mean gap score of -3.07). If kept in mind that tangibles refer to the physical facilities and surroundings; property and equipment of the institution; and the appearance of the staff, then the feedback of the focus group interviewees are enlightening when they proffer that:

- Construction activities underway at universities create an impression of neglect; for example, roads are in a state of disrepair; 
- Offices are not professionally furnished; and

- Poor amenities are offered on campus. An illustrative example being that no lounges or recreation centres are offered on campus.

These findings imply that the improvement plan set by the "TO BE" design of the BPR documents of the universities (MU, 2008; HU, 2008) was not met. Smith et al. (2007) arrived at similar conclusions. The interview participants believed that the poor upkeep of tangibles (the visual appeal - how service staff dress and how visually appealing facilities are) would have a significant impact on stakeholders' experience of their institutions' service quality. Limited allocation of budgets from the central government, lack of experience and knowledge on the part of the service providers and newness of the university are also mentioned as reasons for the unsatisfactory state of affairs.

Finally, the focus group participants were asked what changes they would make in order to improve the service quality of their universities, if full authority and resources were given to them. After laughing for a while, all the participants made the following proposals:

- The reliability dimension of service quality should be improved first.

- The attitudes of the service providers should be changed first in terms of considering themselves as civil servants, employed to serve the stakeholders and to act as servants for those whom they served.

- Human and material resources should be provided according to the standards set for universities.

- Necessities such as internet access, transport and computers ought to be provided.

- Staff should be motivated to work towards a common goal. The person who mentioned this point shared what she had read in the newspaper: There was a janitor working in a satellite launching station. While performing his regular duty, a person asked, "What are you doing here?" He responded, "I am cleaning the rooms to launch a satellite." All staff should have this feeling in order to bring the expected service quality improvement initiatives.

- Proper implementation of BPR.

- Adequate training of all staff on how to provide a service to their stakeholders.

- Providing incentives based on outstanding performance.

- Improving the tangibles dimensions of service quality.

- Appointing staff according to their training, experience and merit.

- Open discussions with all staff on how to improve the service quality of the university and collecting information from them and planning together.

- Appointing reform officers.

- Creating strong controlling mechanisms and structures.

In general, the focus group interviews led to the identification of a number of important findings from the focus group interviews which supplement the findings derived from the quantitative data.

\section{Conclusions}

As indicated in the results section, four factors or dimensions were found to underlie the service quality data structure of Ethiopian PHEIs. The research aim of determining the dimensionality of the Ethiopian specific SERVQUAL dataset could thus be addressed.

Service quality is judged as excellent when service quality performance meets or exceeds the expectations of stakeholders. Negative mean gap scores were however reported for the current study and these negative scores are areas in Ethiopian PHEls that require improvement in the attainment of service quality satisfaction perceptions of academic staff.

In this study, the major contributors to the gap between stakeholders' perception and expectations of service quality were the reliability and tangibles dimensions followed by the assurance dimension. The reliability dimension is consistent with the findings of Brysland and Curry (2001) and Smith et al. (2007). The reliability dimension of service quality is an essential component of quality service delivery and the considerable mean gap scores for the reliability construct clearly signal that academic staff hold the perception that the services had not improved as stated in the BPR "TO BE" document (MU, 2008; HU, 2008).

Academic staff also expressed their dissatisfaction with the tangibles service quality dimension. This service construct refers to the physical facilities and surroundings, equipment and apparatus of the institution which provide services. It also includes staff appearance. This finding implies that the tangibles dimension of the institution does not comply with the improvement plan set by the "TO BE" design of the BPR documents of the universities (MU, 2008; HU, 
2008). Smith et al. (2007) have arrived at a similar conclusion. It is interesting to note that the third dysfunctional service area pointed to assurance. This shows a lack in the service provider's knowledge and ability to instil confidence in stakeholders on the issue of service delivery.

The conclusion can be made that the reliability and tangibles (followed by assurance) service dimensions have been identified as falling critically short of academic staff expectations in service quality improvement initiatives at public higher education institutions in Ethiopia. The gap analysis indicated a good measure of service quality dissatisfaction as evaluated by the academic staff, and their assessments indicated that for the Ethiopian higher education system, these dimensions are in great need of service quality improvement.

\section{Recommendations}

A few recommendations which follow from the findings of the research are discussed as concluding remarks.

Regarding the reliability attributes of quality service it is recommended that the university management put a BPR implementation monitoring office in place so that a one-stop service is provided to the stakeholders. This office can oversee the quality of service offered and collect grievances and take the necessary action. Decision-making should also be decentralised to the point where the service is delivered to customers.

Regarding results concerning the tangibles aspects of service, it is recommended that institutions pay attention to the visual appeal of their premises; provide sufficient and adequate office space, classrooms, laboratories and workshops, as well as effective printing and publishing facilities. Since students frequent the cafeteria on a regular basis, cafeteria facilities improvements should attend to a hygienic and attractive environment.

It is also recommended that certain key values and beliefs be adopted by all PHEI staff, namely, honesty, discipline, fairness (aforementioned pertaining to the identified reliability dimension), customer-satisfaction oriented service (empathy dimension), responsiveness (responsive dimension), transparency and other decision-making or conflict resolution attributes (which should embrace the identified dimensions of assurance, responsiveness and empathy) that affect service delivery and which are indicated in the BPR documents. The following truth should be stressed to the staff: "Customers pay all our salaries: I will go the extra mile to accommodate realistic queries and requests of the customer".

Finally, Parasuraman et al. (1988), advocate the use of the SERVQUAL scale to measure service quality periodically in combination with other forms of service quality measures. It is recommended that this strategy be followed in order to continuously focus on quality improvement of Ethiopian $\mathrm{HEI}$ service delivery.

\section{References}

Ayalew, S, Dawit M, Tesfaye S \& Yalew, E. 2009. Assessment of science education quality indicators in Addis Ababa, Bahir Dar and Hawassa Universities. In: Taye Assefa (ed.). Quality of Higher Education in Ethiopian Public Institutions, Addis Ababa: Forum for Social Science.

Brysland, A \& Curry, A. 2001. Service improvements in public services using SERVQUAL. Managing Service Quality, 11(6):389-401.

Chen, S, Yang, C, Lin, W \&Yeh, T. 2007. Service quality attributes determine improvement priority. The TQM Magazine. 19(2):162-175.

Chen, S, Yang, C, Shiau, J \& Wang, H. 2006. The development of an employee satisfaction model for higher education. The TQM Magazine, 18(5): 484-500.

Cronin, J \& Taylor, S. 1992. Measuring service quality: A re-examination and extension. Journal of Marketing, 56:55-68.

Faganel, A. 2010. Quality perception gap inside the higher education institution. International Journal of Academic Research, 2(1):213215.

Fernandez, M \& Bedia, A. 2005. Applying SERVQUAL to diagnose hotel sector in a tourist destination, Journal of Quality Assurance in Hospitality \& Tourism, 6(1):9-24.

Field, A. 2005. Discovering statistics using SPSS. (2nd ed.). London: Sage Publications.

Firdaus, A. 2006. The development of HEdPERF: a new measuring instrument of service quality for the higher education sector. International Journal of Consumer Studies, 30(6):569-81.

Gallifa, J \& Batalle, P. 2010. Student perceptions of service quality in a multi-campus higher education system in Spain. Quality Assurance in Education, 18(2):156-170.

Gapp, R \& Fisher, R. 2006. Achieving excellence through innovative approaches to student involvement in course evaluation within the tertiary education sector. Quality Assurance in Education, 14(2):156-66.

Grunberg, T. 2003. A review of improvement methods in manufacturing operations. Work Study, 52(2):34.

Hawassa University 2009b. Business Processes Re-engineering document: Supportive process. Unpublished document. Hawassa University. 
2008. Business Process Re-engineering (BPR): Understanding \& mapping the current process, 'As Is'. Unpublished document. Hawassa University.

Johnston, R \& Kong, X. 2011. The customer experience: a road-map for improvement. Managing Service Quality, 21(1):5-24.

Jongbloed, B, Enders, J \& Salerno, C. 2008. Higher education and its communities: Interconnections, interdependencies and research agenda. Higher Education, 56(3):303-324.

Joseph, M \& Joseph, B. 1997. Service quality in education: a student perspective. Quality Assurance in Education, 5(1):15-21.

Juga, J \& Juntunen, J. 2010. Service quality and its relation to satisfaction and loyalty in logistics outsourcing relationships. Managing Service Quality, 20(6):15-23.

Koslowski, F. 2006. Quality and assessment in context: A brief review. Quality Assurance in Education, 14(3):277-88.

Lodico, M, Spaulding, D, \& Voegtle, K. 2006. Methods in educational research: From theory to practice. San Francisco, CA: John Wiley \& Sons.

Martilla, J \& James, J. 1977. Importance-performance analysis. The Journal of Marketing, 41(1):77-79.

Mehralizadeh, Y \& Massoud, S. 2010. The applicability of quality management systems and models to higher education. The TQM Journal, 22(2):175-187.

Mekelle University. 2008. Business process re-engineering /BPR/: Academic core process re-engineering (ACPR). Unpublished document. MU.

Miao, W, Jiaxin, W \& Jinlin, Z. 2007. An empirical study of the effect of customer participation on service quality. Journal of Quality Assurance in Hospitality \& Tourism, 8(1):49-73.

Ministry of Education (MoE), 2009. Education statistics annual abstract. Addis Ababa: Education sector development programme planning and analysis department.

2005. Education sector development programme III (ESDPIII): Programme action plan. Addis Ababa: Ministry of Education Education management information system department. 2011. Education statistics annual abstract. Addis Ababa: EMIS.

Mizikaci, F. 2006. A systems approach to programme evaluation model for quality in higher education. Quality Assurance in Education, 14(1):37-53.

Mostafa, M. 2007. A comparison of SERVQUAL and I-P Analysis: Measuring and improving service quality in Egyptian private universities. Journal of Marketing for Higher Education, 16(2):83-104.

Nadiri, H, Kandampully, J \& Hussain, K. 2009. Students' perceptions of service quality in higher education. Total Quality Management, 20(5):523-535.

O'Neill, M. \& Palmer, A. 2004. Importance-Performance Analysis: A useful tool for directing continuous quality improvement in higher education. Quality Assurance in Education, 12(1):39-52.

Pansiri, J \& Mmereki, R. 2010. Using the SERVQUAL Model to evaluate the impact of public service reforms in the provision of primary health care in Botswana. Journal of African Business, 11(2):219-234.

Parasuraman, A, Zeithaml, V \& Berry, L. 1988. SERVQUAL: A multiple-item scale for measuring consumer perceptions of service quality. Journal of Retailing, 64(1):12-40. 1991. Refinement and reassessment of the SERVQUAL scale. Journal of Retailing, 67(4):420-450.

Pariseau, S \& McDaniel, J. 1997. Assessing service quality in schools of business. International Journal of Quality \& Reliability Management, 14:204-218.

Quinn, A, Lenay, G, Larsen, P \& Johnson, D. 2009. Service quality in higher education. Total Quality Management, 20(2):139-152.

Ramseook-Munhurrun, P, Naidoo, P \& Lukea-Bhiwajee, S. 2009. Employee perceptions of service quality in a call centre. Managing Service Quality, 19(5):541-557.

Saint, W. 2004. Higher education in Ethiopia: The vision and its challenges. Working paper series. Washington, DC: World Bank.

Shah, A. 2009. The impact of quality on satisfaction, revenue, and cost as perceived by providers of higher education. Journal of Marketing for Higher Education, 19:125-141.

Smith, G, Smith, A \& Clarke, A. 2007. Evaluating service quality in universities: a service department perspective. Quality Assurance in Education, 15 (3):344- 351.

Solomon L. Lodesso 2013." Stakeholder perceptions of service quality improvement in Ethiopian public higher education institutions", unpublished doctoral thesis, Unisa

Teas, RK. 1993a. Expectations, performance evaluation, and consumers' perceptions of quality. Journal of Marketing, 57(4):18-34. 1993b. Consumer expectations and the measurement of perceived service quality. Journal of Professional Services Marketing, 8(2):33-54.

Teshome, Y. 2003. Transformations in higher education: Experiences with reform and expansion in the Ethiopian higher education system. Keynote speech presented at an Africa Regional Training conference 'Improving tertiary education in Sub-Saharan Africa: Things that work!' held in Accra, Ghana on September 23-25.

Vakola, M \& Rezgui, Y. 2000. Critique of existing business process re-engineering methodologies: The development and implementation of a new methodology. Business Process Management Journal, 6(3):238-250.

Wang, M, Wang, J \& Zhao, J. 2007. An empirical study of the effect of customer participation on service quality. Journal of Quality Assurance in Hospitality \& Tourism, 8(1):49-73.

World Bank 2004. Higher education development for Ethiopia: Pursuing the vision. Washington DC: World Bank. 
Wright, C \& O'Neill, M. 2002. Service quality evaluation in the higher education sector: An empirical investigation of students' perceptions. Higher Education Research \& Development, 21(1):23-39.

Zafiropoulos, C \& Vrana, V. 2008. Service quality assessment in a Greek higher education institute. Journal of Business Economics and Management, 9(1): 33-45. 